Cilt/Volume:13 Sayı/Issue:3 Aralık/December 2021 Özel Sayı/ Special Issue

\title{
Tikso Şekillendirme ile Üretilen A356 Alaşımında Sıkıştırma Süresinin Mikro Yapı ve Sertlik Üzerine Etkisi
}

\section{Effect of Compression Time on Microstructure and Hardness of A356 Fabricated via Thixoforming}

\author{
Bekir Yavuzer $^{*}$ iD, Dursun Özyürek ${ }^{2}$ iD \\ ${ }^{1}$ Beykent Üniversitesi Mühendislik Mimarlık Fakültesi Makine Mühendisliği Bölümü, 34075 ve İstanbul, TÜRKIYYE \\ ${ }^{2}$ Karabük Üniversitesi Teknoloji Fakültesi Imalat Mühendisliği Bölümü, 78050 ve Karabük, TÜRKIYYE
}

Başvuru/Received:07/10/2021

Kabul / Accepted: 25/12/2021

Çevrimiçi Basım / Published Online: 31/12/2021

Son Versiyon/Final Version: 31/12/2021

\begin{abstract}
$\ddot{O} \mathbf{z}$
Bu çalışmada yarı-katı şekillendirme yöntemlerinden biri olan tikso şekillendirme işlemi A356 alaşımına uygulanmıştır. Sıkıştırma süresinin ve ön şekillendirilen tozların deformasyonunun, alaşımın mikro yapı ve sertlik özelliklerine etkisi incelenmiştir. Tikso şekillendirmede gaz atomizasyonu (argon) ile üretilen ortalama boyutu $\leq 50 \mu \mathrm{m}$ olan A356 tozları kullanılmıştır. Üretilen A356 alaşımı tozları iki gruba ayrılmış ve bir grup mekanik öğütme işlemine tabi tutularak, diğer grup ise üretildiği gibi metal kalıpta sıkıştırılarak (800 Mpa) ön şekillendirilmiştir. Ön şekillendirilmiş parçalar yarı-katı işlem ünitesinde $590{ }^{\circ} \mathrm{C}$ firın ve $350{ }^{\circ} \mathrm{C}$ kalıp sıcaklığında yarı katı halde sıkıştırılmıştır. Mikro yapı incelemeleri sonucunda sıkıştırma süresineki artışa bağlı olarak tanelerin küreselleşme miktarında artış olduğu, tane boyutlarında ise azalma meydana geldiği belirlenmiştir. En yüksek küresellik oranı, ögütme işlemi uygulanmamış ve tikso şekillendirme işleminde 2 dakika sıkıştırma süresi kullanılmış olan tikso işlem uygulanmış A356 alaşımında ölçülmüştür. Numunelerin farklı bölgelerinden alınan sertlik ölçümleri sonucunda, dış cidardan merkeze doğru alınan sertlik değerlerinde azalma olduğu görülmüştür. En yüksek sertlik değeri öğütme işlemi uygulanmamış ve 2 dakika sıkıştırılarak üretilmiş tikso işlem uygulanmış A356 alaşımından elde edilmiştir. Ayrıca EDS analizi sonuçlarında tane sınırlarındaki silisyum müktarının, tane içinde çözünen silisyum miktarından daha fazla olduğu belirlenmiştir.
\end{abstract}

\section{Anahtar Kelimeler}

"A356, Tikso şekillendirme, Mikro yapı, Sertlik"

\begin{abstract}
In this study, thixo forming process, which is one of the semi-solid forming methods, was applied to A356 alloy. The effects of compression time and deformation of preformed powders on microstructure and hardness properties of the alloy were investigated. A356 powders with an average size of $\leq 50 \mu \mathrm{m}$ produced by gas atomization (argon) were used in thixoforming. Produced A356 alloy powders were divided into two groups and one group was subjected to mechanical milling process and the other group was preformed by compression in a metal mold $(800 \mathrm{Mpa})$ as it was produced. The preformed parts were compressed in a semi-solid process unit at a furnace temperature of $590^{\circ} \mathrm{C}$ and a mold temperature of $350^{\circ} \mathrm{C}$ in semi-solid state. As a result of the microstructure investigations, it was determined that there was an increase in the amount of sphericity of the grains, and a decrease in the grain size, depending on the increase in the compaction time. The highest sphericity ratio was measured in the thixo-treated A356 alloy, which was not milled and used a compression time of 2 minutes in the thixo forming process. As a result of the hardness measurements taken from different parts of the samples, it was observed that there was a decrease in the hardness values taken from the outer wall towards the center. The highest hardness value was obtained from the thixo-treated A356 alloy, which was produced by compression for 2 minutes and not mechanical milling. In addition, in the results of the EDS analysis, it was determined that the amount of silicon at the grain boundaries was higher than the amount of silicon dissolved in the grain.
\end{abstract}

Key Words

"A356, Thixoforming, Microstructure, Hardness"

*Sorumlu Yazar: bekiryavuzer@beykent.edu.tr 


\section{Giriş}

Alüminyum alaşımları, günümüzde neredeyse her alanda kullanılan bir malzeme grubudur. Bu alaşımların mekanik özellikleri, mikro yapıda in-situ veya ex-situ oluşturulan fazlar ile iyileştirilebilmektedir (Li vd. 2005; Kumar vd. 2008; Qui vd. 2015; Cree vd. 2011; Khosravi vd. 2015; Shabani ve Mazahery, 2011; Mandal vd. 2009). Malzeme üretiminde kullanılan imalat yöntemi ise mikro yapıları ve dolayısıyla malzeme özelliklerini doğrudan etkilemektedir. Geleneksel döküm yöntemiyle üretilen $\mathrm{Al}$ alaşımları, ergiyik halde hava ile temas etmekte ve temas yüzeyinde oksit film tabakası oluşmaktadır. Döküm sırasında türbülanslı akış meydana gelmesi sonucu bu oksit tabakası metal içine karışmakta ve döküm sonrası gözenek olarak tanımlanan hatalara neden olmaktadır. Ayrıca çoğu alüminyum döküm alaşımında \%3-6 oranında çekme olmaktadır. Besleyici kullanılmadığı veya uygun tasarım yapılmadığı sürece, döküm parçanın içinde veya yüzeyinde oluşan çekme hataları, parçanın mekanik özelliklerinin düşmesine neden olmaktadır. Normal katılaşma şartlarında ötektik altı alüminyum döküm alaşımlarının mikro yapıları kimyasal bileşimlerine bağlı olarak, $\alpha$-alüminyum taneleri ve bu taneleri çevreleyen ötektik alaşımından meydana gelmektedir. Dentritik yapıdan oluşan bu yapının mekanik özelliklerini geliştirmek için tane inceltmesi yapmak gerekmektedir (Yıldırım vd. 2017; Otarwanna vd. 2011). Al-Si alaşımlarına, Ti ve B gibi elementler çeşitli şekillerde (karbür, borür vb.) ilave edilerek tane inceltmek mümkün olmaktadır (Li vd. 2005; Shabani ve Mazahery, 2011, Çam vd. 2016). Yarı-katı üretim yöntemi, klasik kum kalıba döküm yönteminin yukarıda bahsedilen olumsuzluklarını engellemeye imkân vermektedir. Kouji (1997) yapmış olduğu çalışmada; yarı-katı üretim teknolojisi ile üretilen malzemelerin mekanik özelliklerini, klasik döküm yöntemleriyle üretilmiş olan malzemelerin mekanik özellikleriyle karşılaştırmış ve katılaşma sırasındaki hızlı soğuma nedeniyle, yarı-katı üretim ile üretilen malzemelerin darbe, yorulma ve çekme dayanımlarında kayda değer bir artışın görüldüğünü belirtmiştir. Kapronos vd. (1992) yaptığı çalışmada ise, yarı-katı üretim teknolojisinde, diğer üretim yöntemlerinin yüksek sıcaklık alaşımlarına göre daha iyi olduğunu ve kısmi ergime aralığındaki dentritsiz yapıların, yarı-katı halde dövülebilirliğinin iyileştirildiğini göstermektedirler. Witulski vd. (1998) bazı özel niteliklere sahip alaşımların (özellikle A356/357 gibi yarı-katı işlem yapılabilen), yüksek sıcaklıklara çıkıldığında çatlamasına rağmen, tikso kalıplama işleminin mükemmel bir şekilde yapılabileceğini belirmişlerdir.

Yarı-katı malzemeler hem katı hem de sıvıya benzer davranışlar göstermektedirler. Katı malzeme özelliği göstererek katının iç yapısını büyük oranda korurken, sıvı gibi davranarak kalıp boşluğunu kolaylıkla doldurabilmektedir (Atkinson, 2005). Yarı-katı döküm yöntemi ile üretilen malzemeler, mikro yapının homojen olması ve daha az gözenek içermesi nedeniyle, daha üstün mekanik özellikler sergilemektedirler. Tikso kalıplama yöntemi de yarı-katı bölgede malzemenin şekillendirildiği bir yöntemdir. Tikso kalıplama yöntemi, yarı-katı şekillendirme yöntemi ile karşılaştırıldığında, en belirgin fark, kalıplama işleminin sıvı bölgeden yarı-katı bölgeye geçerken değil, katı bölgeden yarı-katı bölgeye geçilerek yapılmasıdır. Tikso kalıplama yönteminde tozlar, yarı-katı hale getirildikten sonra belirli bir basınç altında kalıp boşluğunu doldurmaktadır. Tikso kalıplama için genellikle yarı-katı malzemedeki sıvı oranı \%30-50 aralığında olmakla birlikte mikro yapının küresel olması büyük önem arz etmektedir (Atkinson, 2005; Jung ve Kang, 1999). Jung (2000) yapmış olduğu bir çalışmada tikso kalıplama yöntemi ile şekillendirilen A356 alaşımının indüksiyon sistemi ile ısıtılmasının, alaşımın mikro yapısı üzerine olan etkilerini araştırmıştır. Bu çalışma, tikso kalıplama yöntemi ile şekillendirmede mikro yapının, kademeli ısıtma sıcaklıkları ile birlikte, ısıtma ve sıkıştırma süresinden de etkilendiğini göstermektedir. Cho vd. (2000) yapmış oldukları bir çalışmada, tikso kalıplama ile şekillendirilen alüminyum alaşımlarında sıkıştırma sırasında uygulanan yük arttıkça, mikro yapıdaki gözeneklerin azaldığını ve yoğunluğun arttı̆̆ını bildirmektedirler. Literatürdeki çalışmalar, tikso kalıplama ile şekillendirilen parçaların mikro yapılarının, alaşımın ön ısıtmada ulaşılan sıcaklıktan (Cho vd. 2000), sıkıştırma basıncından (Cho vd, 2000; Idegomori vd. 1998; Pinsky vd. 1984; Kang ve Jung, 2001), sıkıştırma hızından (Lee vd. 2003; Yoshida vd. 1992; Dong vd. 2002), sıkıştırma ve firın içi bekleme süresinden (Dong vd. 2002; Jung, 2000) ve kalıp malzemesinden etkilendiğini göstermektedir.

Bu çalışmada ticari olarak önemli bir kullanım alanı olan A356 alüminyum alaşımına tikso kalıplama yöntemi uygulanmıştır. Yarı-katı 1sıtma öncesi malzeme olarak A356 tozları sıkıştırılmıştır. Tikso kalıplama yönteminde önemli bir değişken olan sıkıştırma süresinin, A356 alaşımının mikro yapı ve sertliğe olan etkisi incelenmiş̧ir.

\section{Malzeme ve Method}

Deneysel çalışmalarda, A356 alaşımı külçelerinden elde edilen tozlar kullanılmıştır. Külçeler, gaz atomizasyon ünitesinde atomize edilerek A356 tozları elde edilmiştir. Toz üretiminde soy gaz olarak argon kullanılmıştır. Nozullardan geçen gaz basıncı 32 atm'dir. Üretilen tozların ortalama boyutu $\leq 50 \mu \mathrm{m}$ 'dir. Toz tartım işlemleri Precisa XB200h marka 1/10000 hassasiyetteki terazide yapılmıştır. Üretilen A356 tozları iki gruba ayrılmış ve bir grup ilave herhangi bir işlem görmeden, oda sıcaklığında, 800 MPa basınç altında metal kalıpta sıkıştırılarak ön şekillendirilmiştir. Ön şekillendirilen parçalar, $12 \mathrm{~mm}$ çap ve $35 \mathrm{~mm}$ yüksekliğinde silindir şeklindedir. Diğer grup ise deformasyonun mikro yapı üzerindeki etkisinin belirlenmesi amacıyla mekanik öğütme işlemine tabi tutulduktan sonra, birinci gruba uygulanan ön şekillendirme parametreleri kullanılarak ön şekillendirilmiştir. Mekanik öğütme işlemlerinde, 10:1 bilya/toz oranı, 30 dakika ögütme süresi ve $\% 50$ kap doluluk oranı seçilmiştir. Tozların soğuk sıkıştırılması ile üretilen A356 parçalar, yarı-katı işlem ünitesinde $590{ }^{\circ} \mathrm{C}$ fırın ve $350^{\circ} \mathrm{C}$ kalıp sıcaklığında yarı-katı halde sıkıştırılmıştır. Sıkıştırma işleminde, kalıp malzemesi olarak grafit kullanılmıştır. 1 ve 2 dakika olmak üzere iki farklı sürede sıkıştırma işlemi gerçekleştirilmiştir. Üretim parametreleri ve numaralandırmaları Tablo 1'de verilmektedir. 
Tablo 1. Tikso kalıplama yöntemi ile üretilen A356 alaşımlarının üretim şartları

\begin{tabular}{cc}
\hline No & Üretim Şartları \\
\hline A1 & Öğütülmemiş tozlar, 1 dakika yarı-katı sıkıştırma \\
A2 & Öğuttülmemiş tozlar, 2 dakika yar1-katı sıkıştırma \\
B1 & 30 dakika öğütülmüş tozlar, 1 dakika yarı-katı sıkıştırma \\
B2 & 30 dakika öğütülmüş tozlar, 2 dakika yarı-katı sıkıştırma \\
\hline
\end{tabular}

Üretilen tikso işlem uygulanmış A356 alaşımların mikro yapılarında herhangi bir değişim olmaması için su soğutma ortamında kesilmiş

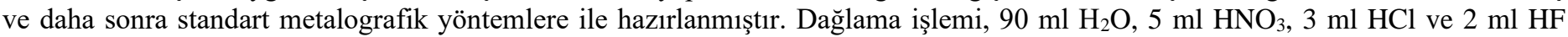
solüsyonunda $30 \mathrm{~s}$ süre ile yapılmıştır. Optik mikroskop görüntüleri, MEIJI ML 7100 marka mikroskop ve BOSH DINION XF kamera kullanılarak elde edilmiştir. Taramalı elektron mikroskobu (SEM) incelemeleri JEOL JSM-6060 model taramalı elektron mikroskobunda yapılmıştır. Mikro yapı tanelerinin, tane boyutu ve küresellik ölçümleri MSQ PLUS 6.5 adlı metalografik ölçüm ve analiz programında ASTM E112 standartlarına göre yapılmıştır. Sertlik ölçümleri AFFRI VRSD251 marka cihazda HV 2,5 yük altında, numunenin çevresinden merkezine doğru 3 farklı bölgesinden alınan ölçümlerin ortalaması alınarak yapılmıştır.

\section{Bulgular ve Değerlendirme}

\subsection{Mikro yapı sonuçları}

Farklı sıkıştırma sürelerinde tikso yöntemiyle şekillendirilmiş A356 alaşımlarının optik mikroskop görüntüleri Şekil 1'de verilmektedir.
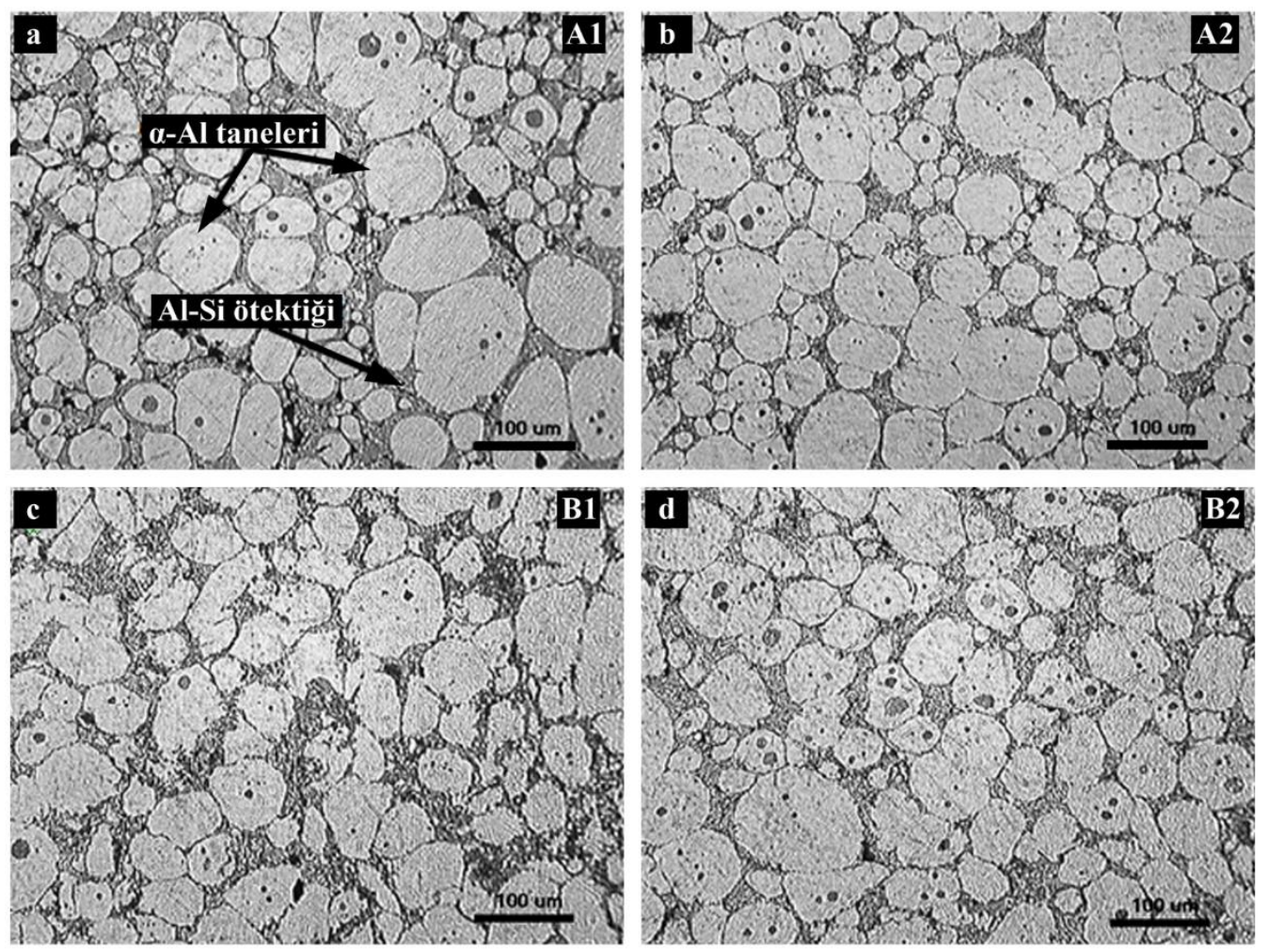

Şekil 1. Farklı sıkıştırma sürelerinde üretilmiş A356 alaşımlarının optik mikroskop görüntüleri (a) A1; (b) A2; (c) B1; (d) B2

Şekil 1'de verilen mikro yapı görüntülerinden, tüm tikso işlem uygulanmış A356 alaşımların mikro yapıları $\alpha$-alüminyum tanelerinden ve Al-Si ötektik bileşiminden oluşmuş fazdan meydana geldiği görülmektedir. Küresel $\alpha$-alüminyum taneleri içinde koyu renkli Al-Si ötektik fazının bulunduğu da anlaşılmaktadır. Bu yapı tikso kalıplama yönteminde elde edilebilmektedir (Otarawanna vd. 2011; Şimşek vd. 2020). Şekil 2'de 2 dakika süre ile sıkıştırılmış tikso işlem uygulanmış A356 alaşımın EDS analiz sonuçları verilmektedir. 


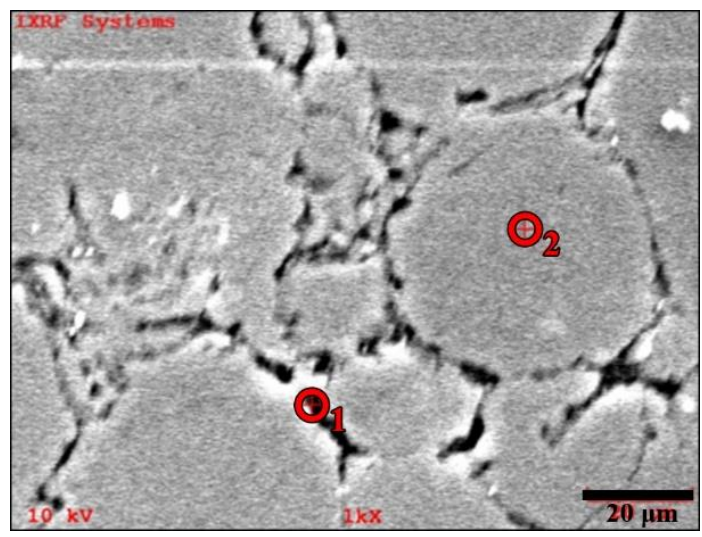

\begin{tabular}{llll}
\hline Analiz & Al (\%) & $\mathbf{S i}(\boldsymbol{\%})$ & $\mathbf{M g}(\boldsymbol{\%})$ \\
\hline $\begin{array}{l}\text { Tane } \\
\text { Sinırı }\end{array}$ & 91,156 & 4,460 & 0,384 \\
\hline Matris & 99,128 & 0,476 & 0,396 \\
\hline
\end{tabular}

Şekil 2. 2 dakika sıkıştırma süresinde üretilmiş A356 alaşımından alınan EDS analiz sonuçları

Şekil 2'de verilen EDS analiz sonuçları incelendiğinde tane sınırlarında bulunan silisyum miktarının, tanelere oranla yaklaşık 10 kat daha fazla olduğu görülmektedir. Tikso prosesi, sıkıştırma başıncı ve zamanına bağlı olarak oluşan itici güç ile birlikte, toz tanesi içindeki silisyum elementinin tane sınırlarına difüzyonuna yol açmıştır. Şekil 3'de farklı sıkıştırma sürelerinde üretilmiş A356 alaşımlarının mikro yapı tane boyutu ve küresellik ölçüm sonuçları verilmektedir.
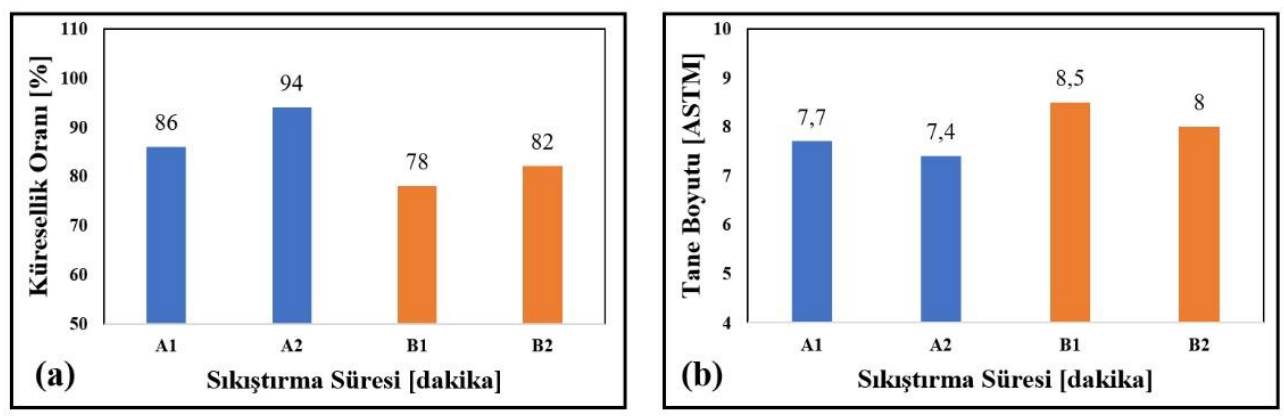

Şekil 3. Farklı sıkıştırma sürelerinde üretilmiş A356 alaşımlarının; a) Küresellik ve b) Tane boyutu ölçüm sonuçları

Mikro yapı tane inceltmesinin, Al-Si alaşımlarının mekanik özelliklerinin değişiminde önemli bir rol oynadığı bilinmektedir (Khalifa vd. 2015). Şekil 3'de verilen sonuçlar incelendiğinde tikso şekillendirmede sıkıştırma süresinin tane boyutu ve küresellik oranı üzerine etkili olduğu görülmektedir. 1 dakika sıkıştırılarak üretilen A1 numunesinde küresellik oranı \%86 iken, bu oran 2 dakika sıkıştırma süresinde (A2) \%94'e çıkmaktadır. Şekil 3.b'deki tane boyutu ölçüm sonuçları incelendiğinde, sıkıştırma süresinin 1 dakikadan 2 dakikaya çıktığında, tane boyutunun 7.7'den 7.4'e düştüğü görülmektedir. Mekanik öğütme işlemi uygulanan tozlardan üretilen tikso işlem uygulanmış A356 alaşımlarda da (B1 ve B2) benzer sonuçlar görülmektedir. Öğütülmüş̧ tozlardan üretilen ve 1 dakika yarı-katı sıkıştırma uygulanan A356 alaşımında (B1) küresellik oranı \%78 (Şekil 3.a), tane boyutu ise 8,5 (Şekil 3.b) olarak ölçülmüştür. Yarıkatı şekillendirmede sıkıştırma süresini 2 dakikaya çıkarıldığında ise (B2), küresellik oranı \%82'ye çıkmış, tane boyutu ise 8 'e düşmüş̧ür. Ancak öğütme işlemi uygulanan alaşımlar, öğütme işlemi uygulanmayan tozlar ile karşıllaştırıldığında hem küreselleşme oranında hem de tane boyutu incelmesinde daha etkisiz olmaktadır. Atomizasyon ile üretilen tozların küresel şekillerde oluştuğu bilinmektedir. Ancak öğütme işlemi ile küresel şekilli tozlar bilya-bilya veya bilya-kap arasında kalarak ezilmekte, kırılmakta ve kaynaklanmaktadır (Çam vd. 2016). Tikso kalıplama işlemi uygulanacak alaşımın mikro yapısının küresellik oranı yüksek tanelerden oluşması, tikso kalıplama sonrası oluşacak mikro yapının küresellik oranını arttırmaktadır.

\subsection{Sertlik sonuçları}

Şekil 4'de 2 farklı sürede sıkıştırılarak üretilmiş A356 alaşımlarının sertlik ölçümleri verilmektedir. 


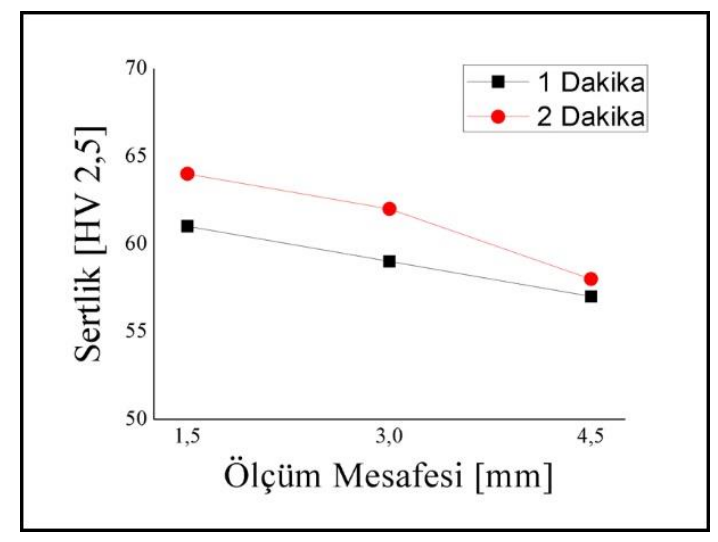

Şekil 4. Farklı sıkıştırma sürelerinde üretilmiş A356 alaşımlarının sertlik ölçüm sonuçları

Şekil 4'de verilen sertlik ölçüm sonuçları incelendiğinde, sıkıştırma süresinin artmasıyla birlikte sertlik değerlerinde artış olduğu görülmektedir. Şekil 3'de verilen tane boyutu ve küresellik oranı sonuçları ile birlikte ele alındığında, bu sonuçlar beklentiler doğrultusunda olmaktadır. Tane boyutu ile akma dayanımı arasında ilişki Hall-Petch eşitliği (Eşitlik 1) ile açılanmaktadır.

$$
\sigma_{y}=\sigma_{0}+k_{y} d^{-1 / 2}
$$

Burada $\sigma_{\mathrm{y}}$ : akma dayanımı, $\sigma_{0}$ : dislokasyon hareketini başlatmak için gereken gerilim, k: mukavemetlendirme katsayısı ve d: tane boyutudur. Bu eşitlikten de anlaşııldığı üzere, malzeme dayanımı artışı tane boyutu ile doğrudan ilişkilidir. Ayrıca mikro yapıda bulunan fazların şekilleri de, malzeme dayanımına etki etmektedir (Haghshenas vd. 2009). Şekil 3.a'da verilen sonuçlardan, tanelerin küreselleşme oranlarının artması, A356 alaşımının sertliğinin de artmasına neden olmaktadır. Bu duruma ek olarak Cho ve Kang (2000), yaptıkları bir çalışmada çekme ve akma mukavemetlerindeki artışın, yüksek sıkıştırma basıncının sonucu yoğunluğun artması ve gözeneklerin azalması sonucunda elde edildiğini rapor etmişlerdir. Ayrıca Şekil 4'de verilen sertlik ölçüm sonuçları incelendiğinde, sertlik değerlerinin numunenin merkezine yaklaştıkça azaldığı anlaşılmaktadır. 1 dakika süre ile sıkıştırılmış tikso işlem uygulanmış A356 alaşımında, kenardan merkeze doğru yaklaşıldıkça ölçüm değerleri 61, 59 ve 57 HV olarak ölçülürken, 2 dakika sıkıştırılmış alaşımdan alınan ölçümler numunenin kenarından merkeze doğru gidildikçe, 64, 62 ve 58 HV olarak ölçülmüştür. Idegomori vd. (1998) yapmış oldukları bir çalışmada, basıncın etkisiyle sıvı faz oranının numunenin merkezine oranla kenar bölgelerde daha fazla olduğunu ve bu nedenle merkezdeki sertliğin kenar bölgelerden daha düşük değerde olacağını belirtmişlerdir. Şekil 4'de verilen sertlik ölçüm sonuçları göz önüne alındığında elde edilen sonuçların, Idegomori vd. (1998) yapmış oldukları çalışma ile paralel olduğu görülmektedir.

\section{Sonuçlar}

- Yarı-katı şekillendirme yöntemiyle üretilen tikso işlem uygulanmış A356 alaşımı küresel bir mikro yapı elde edilmiştir.

- Üretilen alaşımların mikro yapısının $\alpha$-Al küresel taneler ve bu taneleri çevreleyen Al-Si ötektiği olduğu anlaşılmıştır.

- Sıkıştırma süresinin mikro yapı üzerinde etkili olduğu, 2 dakika süre ile sıkıştırılarak üretilen A356 alaşımının, 1 dakika süre ile üretilen alaşımla kıyaslandığında, küresellik oranının daha fazla olduğu, tane boyutunun ise daha ince olduğu belirlenmiştir.

- Üretilen alaşımların sertliklerinin sıkıştırma süresindeki artışla birlikte arttığı belirlenmiştir.

\section{Referanslar}

Atkinson, H. V. (2005). Modelling the semisolid processing of metallic alloys. Progress in Materials Science, 50(3), $341-412$. doi:10.1016/j.pmatsci.2004.04.003

Cho, W. G., \& Kang, C. G. (2000). Mechanical properties and their microstructure evaluation in the thixoforming process of semi-solid aluminum alloys. Journal of Materials Processing Technology, 105(3), 269-277. doi: 10.1016/S0924-0136(00)00577-X

Cree, D., \& Pugh, M. (2011). Dry wear and friction properties of an A356/SiC foam interpenetrating phase composite. Wear, 272(1), 88-96. doi: 10.1016 / j.wear.2011.07.008

Çam, S., Demir, V., \& Özyürek D. (2016). Wear behaviour of A356/TiAl3 in situ composites produced by mechanical alloying. Metals, 6(2):34. doi: $10.3390 /$ met6020034

Dong, J., Cui, J. Z., Le, Q. C., \& Lu, G. M. (2002). The key laboratory of electromagnetic processing of material, ministry of education. Northeastren University, SHENYANG. 
Haghshenas, M., Zarei-Hanzaki, A., \& Jahanzi, M. (2009). An investigation to the effect of deformation-heat treatment cycle on the eutectic morphology and mechanical properties of a Thixocast A356 alloy. Materials Characterization, 60(8), 817-823. doi: 10.1016/j.matchar.2009.01.020

Idegomori, T., Hirono, H., Ito, O., Kimishima, S., \& Mizoue K., (1998). The manufacturing of automobile parts using semi-solid metal processing. Proceedings of the Fifth International Conference on Semi-Solid Processing of Alloys and Composites, Colorado School of Mines, Colorado.

Jung, H.K., (2000). The induction heating process of semi-solid aluminium alloys for thixoforming and their microstructure evaluation. Journal of Materials Processing Technology, 105(1-2), 176-190. doi: 10.1016/S0924-0136(00)00567-7

Jung, H. K., \& Kang, C. G., (1999). An induction heating process with coil design and solutions avoiding coarsening phenomena of Al-6 Pct Si-3 Pct Cu-0.3 Pct Mg alloy for thixoforming. Matellurgical and Materials Transactions A, 30, 2967-2977. doi: 10.1007/s11661-999-0134-5

Kang, C. G., \& Jung, G. D., (2001). Improvement of the liquid segregation phenomena of semisolid aluminium alloys by the multistage strain rate control in the compression test. Journal of Materials Engineering and Performance, 10 (4) 419-428. doi: $10.1361 / 105994901770344836$

Kapranos, P., Kirkwood, D. H., \& Sellars, C. M. (1992). Semi-solid forging of high temperature alloys. Proceedings of the Second International Conference on Semi-Solid Processing of Alloys and Composites, Massachusetts Institute of Technology of, Massachusetts.

Khalifa, W., El-Hadad, S., \& Tsunekawa, Y. (2015). Microstructure characteristics and tensile property of ultrasonic treated-thixocast A356 alloy. Transactions of Nonferrous Metals Society of China, 25(10), 3173-3180. doi: 10.1016/S1003-6326(15)63949-8

Khosravi, H., \& Akhlaghi, F. (2015). Comparison of microstructure and wear resistance of A356-SiCp composites processed via compocasting and vibrating cooling slope. Transactions of Nonferrous Metals Society of China, 25(8), 2490-2498. doi: 10.1016/S10036326(15)63867-5

Kouji, S. (1997). The characteristics of thixoforming product. Proceedings of the175th JSTP symposium for Semi-Soild Metals Forming, JSTP \& JSME, Tokyo University of Technology, Tokyo.

Kumar, S., Chakraborty, M., Sarma, V. S., \& Murty, B. S. (2008) Tensile and wear behaviour of in situ Al-7Si/TiB2 particulate composites. Wear, 265(1-2), 134-142. doi: 10.1016/j.wear.2007.09.007

Lee, D. H., Seo, P. K., \& Kang, C. G. (2004). Die design by filling analysis of semi-solid injection forging process and their experimental investigation. Journal of Materials Processing Technology, 147(1), 45-50. doi: 10.1016/j.jmatprotec.2003.10.023

Li, P., Kandalova, E. G., \& Nikitin V. I. (2005). In situ synthesis of Al-TiC in aluminum melt. Materials Letters, 59(19-20), 2545-2548. doi: 10.1016/j.matlet.2005.03.043

Mandal, A., Murty, B. S., \& Chakraborty, M. (2009) Sliding wear behaviour of T6 treated A356-TiB2 in-situ composites. Wear, 266(78), 865-872. doi: 10.1016/j.wear.2008.12.011

Otarawanna, S., \& Dahle, A.K. (2011). Fundamentals of aluminium metallurgy. Duxford, Woodhead Publishing.

Pinsky, D. A., Charreyron, P. O., \& Flemings, M. C. (1984) Compression of semi-solid dentritic Sn-Pb alloys at low strain rates. Metallurgical Transactions B, 15, 173-181. doi: 10.1007/BF02661076

Qui, K., Wang, R., Peng, C., Wang, N., Cai, Z., \& Zhang, C. (2015) Effect of individual and combined additions of Al-5Ti-B, Mn and $\mathrm{Sn}$ on sliding wear behavior of A356 alloy. Transactions of Nonferrous Metals Society of China, 25(12), 3886-3892. doi: $10.1016 / \mathrm{S} 1003-6326(15) 64081-\mathrm{X}$

Shabani, M. O., \& Mazahery, A. (2011) Prediction of wear properties in A356 matrix composite reinforced with B4C particules. Synthetic Metals, 161(13), 1226-1231. doi: 10.1016/j.synthmet.2011.04.009

Şimşek, İ., Şimşek, D. \& Özyürek, D. (2020) Yarı Katı Kalıplama Yöntemi İle Üretilen Farklı Miktarlarda SiC Takviyeli A356 Matrisli Kompozit Malzemelerin Aşınma Performansının İncelenmesi. Politeknik Dergisi, 23(4), 1237-1243. doi: 10.2339/politeknik.642506

Witulski, T., Morjan, U., Niedick, I., \& Hirt, G. (1998) The thixoformability of aluminium alloys. Proceedings of the Fifth International Conference on Semi-Solid Processing of Alloys and Composites, Colorado School of Mines, Colorado.

Y1ldırım, M., Özyürek, D., \& Tunçay, T. (2017) The effects of molding materials on microstructure and wear behavior of A356 alloy. High Temperature Materials and Processes, 36(5), 515-521. doi: 10.1515/htmp-2015-0240

Yoshida, C., Moritaka, M., Shinya, S., Takebayashi, K., Nanba, A. (1992) Semi-solid forging of aluminium alloys. Proceedings of the Second International Conference on Semi-Solid Processing of Alloys and Composites, Cambridge, MIT Press. 